\title{
A new thermo-desorption laser-heating setup for studying noble gases diffusion and release from materials at high temperatures
}

\author{
Denis Horlait ${ }^{1, *}$, Rémi Faure ${ }^{1}$, Bertrand A. Thomas ${ }^{1}$, Nicolas Devert ${ }^{1}$, Marie-Lyne Amany ${ }^{2}$, \\ Gaëlle Carlot ${ }^{3}$, Éric Gilabert ${ }^{1}$
}

1) Université de Bordeaux, CNRS, CENBG-IN2P3, F-33170 Gradignan, France

2) CEMHTI, CNRS, UPR3079, University of Orléans, F-45071 Orléans, France

3) CEA, DEN, DEC, F-13108 Saint Paul lez Durance Cedex, France

* Corresponding Author: horlait@ cenbg.in2p3.fr

\begin{abstract}
A new heating and gas treatment line for Thermo-Desorption Spectrometry (TDS) of noble gases ( $\mathrm{He}, \mathrm{Ne}, \mathrm{Ar}, \mathrm{Kr}$ and $\mathrm{Xe}$ ) is presented. It was built with the primary objective to offer advanced temperature controls and capabilities while working in a cold-environment. By choosing a high-power continuous wave laser as an heating source, and using a Proportional-Integral-Derivative (PID) controller system, noble gases TDS can now be performed with fast and highly steady heating ramps (e.g. less than $1^{\circ} \mathrm{C}$ deviation from setpoint for $\leq 1^{\circ} \mathrm{C} \cdot \mathrm{s}^{-1} \mathrm{ramps}$ ). Sample temperature over $2000^{\circ} \mathrm{C}$ can also routinely be reached, with limited heating of the sample support and the sample chamber, offering the possibility to have several samples awaiting in the ultra-high vacuum chamber. We also present development efforts made to increase temperature homogeneity of the heated sample while limiting contacts with the sample holder.
\end{abstract}

Recent results acquired with this TDS setup on krypton thermal diffusion in uranium dioxide $\left(\mathrm{UO}_{2}\right)$ as a function of $\mathrm{O}_{2}$ additions are also presented as an application example.

KEYWORDS: Thermo-Desorption Spectroscopy - Noble Gases - Laser Heating - Nuclear Materials

\section{INTRODUCTION}

Thermo-desorption spectrometry (TDS) [1-6] is a key technique to study as a function of a given heat treatment the release of volatile elements from a material, possibly down to trace levels [1-22]. In the cases of noble gases ( $\mathrm{He}, \mathrm{Ne}, \mathrm{Ar}, \mathrm{Kr}$ and $\mathrm{Xe}$ ), it is particularly convenient to determine characteristic temperatures of gas release [6-9,12-15,18-20], to deduce elemental diffusion kinetics and characteristics (i.e. apparent activation energy of diffusion) [11,14-17], or to help in investigating structural defects $[12-16,19,20]$. Study of noble gases in materials as a function of temperature is particularly relevant for materials encountered in nuclear industry [8-22]. Indeed, He is often largely produced or implanted in core materials of fusion and fission nuclear reactors and in nuclear wastes. In nuclear fuels such as $\mathrm{UO}_{2}$, $\mathrm{Kr}$ and $\mathrm{Xe}$ are also largely produced by actinides fission $(\sim 0.3 \mathrm{Kr}+\mathrm{Xe}$ produced per fission [16]). The gaseous fission products $\mathrm{Xe}$ and $\mathrm{Kr}$ are responsible to unfavourable evolutions of the nuclear fuels (cracking, decrease of thermal conductivity, increase of fuel pin pressure) and are therefore indirectly limiting the achievable fuel burn-ups, in other words reducing the overall energetic yield of nuclear reactors. It is therefore mandatory to reach a comprehensive understanding of $\mathrm{Xe}$ and $\mathrm{Kr}$ diffusion in $\mathrm{UO}_{2}$ and other nuclear fuel candidates. Current knowledge on the subject was recently summarized by Tonks et al. [23]. 
For two decades, our laboratory has realized studies by TDS on noble gases primarily on systems of interest for nuclear materials [12-18], down to trace levels (quantification down to the order of $10^{7}$ atoms of a given noble gas isotope). These studies were done using a molybdenum double jacket furnace in which the sample was heated up to a maximum temperature of $1400^{\circ} \mathrm{C}$. This simple setup, however, had several experimental limitations, the main ones being 1) the maximum operating temperature, 2) limitations in temperatures ramp control (impossibility to impose a controlled heating or cooling ramp), 3) temperature uncertainties, and 4) "noise" effects brought by having a large Mo heated volume (microleaks of the ultra-high-vacuum), inducing disturbances of the ionization step in the mass spectrometer (MS) attributed to unwanted gases presence $\left(\mathrm{H}_{2}, \mathrm{C}_{n} \mathrm{H}_{m}\right.$, Ar, etc.) and 5) the need to break the vacuum between 2 samples. In addition, since the noble gas MS only operates for evident reasons in ultra-high vacuum (UHV, below $10^{-7} \mathrm{mbar}$ ), experiments in the Mo desorption chamber had to be done under UHV conditions as well. Therefore, it was impossible to impose a certain atmosphere onto the treated sample. This was most notably limiting our investigation of $\mathrm{UO}_{2 \pm x}[13,14,16]$ since noble gases diffusion strongly vary as a function of even tiny deviations of $\mathrm{O} / \mathrm{U}$ stoichiometry (i.e. $\mathrm{x}$ value), thus as a function of oxygen partial pressure [24-26]. We therefore developed a new thermo-desorption stage as well as a new gas treatment line to overcome these limitations. Although it was developed specifically for noble gases TDS, its main advantages (temperature features, multi-sample chamber notably) can naturally be transposed to any kind of TDS or even any sample heating chamber setup.

This new setup, L2PAON (French acronym standing for Laser Line for the Optimized Analysis of Nuclear Materials) is here presented and a preliminary result on $\mathrm{O}_{2}$ effect on $\mathrm{Xe}$ diffusion in $\mathrm{UO}_{2 \pm x}$ is given as an application example.

\section{GENERAL DESCRIPTION OF THE TDS SETUP}

The newly installed L2PAON TDS setup was developed on two independent and movable frames, one for the electrical equipment and the other for the UHV components. The latter was connected to pre-existing noble gas mass spectrometers (MS). In-between L2PAON and the MS a network of sampling/fractioning volumes, purification setups, and reference gas reservoirs are installed. This whole setup constitutes the PIAGARA platform (French acronym for Interdisciplinary Platform for the Analysis of Noble Gases) [15,16,27,28]. The whole platform is operated under ultra-high vacuum conditions, as required for the optimal and cautious use of the mass spectrometers and to limit as low as reasonably achievable noble gases contaminations from air. The purification setups comprise SORB$A C{ }^{\circledR}$ traps (SAES Getter, Lainate, Italy) and hot Ti sponges used to remove any chemically reactive species from the gas phase (i.e. all non-noble gases species, most notably $\mathrm{H}_{2}$, hydrocarbons, $\mathrm{H}_{2} \mathrm{O}, \mathrm{O}_{2}$ and $\mathrm{N}_{2}$ ) and charcoals used down to liquid $\mathrm{N}_{2}$ temperature $(96 \mathrm{~K})$ primarily for cryo-separation \& trapping of noble gases. The reference gas reservoirs contain mono-isotopic noble gas standards. Each 1-2 L reservoir is separated from the main UHV network through a duo of valves in-between which a minimal $0.5-1 \mathrm{~cm}^{3}$ volume is found. This allows mixing reference spikes with the sample gas that needs to be analysed. The reference gases are precisely counter-calibrated by air samplings. By this approach of adding precisely-known quantities of a particular isotope, we are routinely able to reach a $\pm 5 \%$ accuracy for noble gas quantification down to ultra-trace levels $\left(10^{8}\right.$ atoms or $10^{-14} \mathrm{~g} / \mathrm{g}$ or $\left.0.01 \mathrm{ppt}\right)$. This $\pm 5 \%$ accuracy finds its main source in the accuracy of the numerous volumes used for an analysis (definition of a volume and of its method of determination presented in the Gas Treatment section).

The TDS L2PAON setup will be presented in two parts: firstly the laser heating and the setups allowing to measure and control the temperature, schematized in Figure 1, and secondly the UHV setup 
(i.e. sampling \& gas purification, $\mathrm{O}_{2}$ additions), pictured in Figure 2. All materials used to build the UHV setup are by default made of 304L stainless steel and using UHV connection ConFlat (CF) standard [29]. UHV sealing at the connections between the different UHV elements are all made using oxygen-free copper gaskets sandwiched by the $304 \mathrm{~L}$ stainless steel knife edges present at both the mating flanges.

\section{LASER HEATING AND TEMPERATURE CONTROL}

Sample chambers. The main chamber presented in Figure 1 (and present as V7 in Figure 2), is aimed at several hours-long TDS experiments. It is based on a DN100CF standard cylinder (interior dimensions: $\mathrm{h}=17.5 \mathrm{~cm}, \varnothing=10.2 \mathrm{~cm}$, KurtLesker, UK). The cylinder placed vertically is closed on its downside by a simple DN100 flange and on its upper side by a Kodial glass viewport (LewVac, UK) mounted on a DN100 flange as well. On the cylinder vertical wall, two opposite DN16CF exits were added on-demand by the manufacturer, one for the connection to the L2PAON setup, the other in case of a currently unforeseen application. As per the project goals, this sample chamber is aimed to offer a cold-working environment and as such the cylinder side is jacketed with a water cooling envelope connected to a chiller (Huber minichiller 600, closed-circuit flow of $18 \mathrm{~L} \cdot \mathrm{min}^{-1}$ ) ensuring optimal heat dissipation and near ambient temperatures for the vertical walls. With the same aim, a large computer fan was readapted to cool down the chamber top viewport (and the optical elements). In the chamber is disposed at the bottom a $13 \mathrm{~mm}$ thick and $70 \mathrm{~mm}$ large stainless steel disk in which four $\sim 1 \mathrm{~mm}$ deep notches are drilled, each aimed to loosely hold one sample holder base (later described).

The second smaller chamber (Vp in Figure 2) has similar specifications. It is built from a generic DN40CF cylinder (interior dimensions: $\mathrm{h}=13 \mathrm{~cm}, \emptyset=3.8 \mathrm{~cm}$ ) and a holed DN16CF flange serves as the unique sample holder base. It also differs by the absence of an integrated cooling system since its aim is to melt $0-100 \mathrm{~mm}^{3}$ sized samples. Therefore although the maximum temperature reached by the sample and its holder can be over $2000^{\circ} \mathrm{C}$ [15], the heat treatment typically only last few minutes and the accumulated heat is thus rather low compared to a long heat treatment performed in the main chamber. A fan is also placed above the viewport, but this rather to protect it from fracturing (a limited but significant fraction of the laser beam gets absorbed by the Kodial glass).

Laser beam and optics. Figure 1 is a schematic view of the heating part of the L2PAON setup. The laser beam exiting at the optic fibre end comes from a LuOcean M2 multimode diode laser (Lumics $\mathrm{GmbH}$, Berlin, Germany). It delivers a 0 to $650 \mathrm{~W}$ continuous wave $933 \pm 10 \mathrm{~nm}$ infrared laser beam, but also an independently switchable $1 \mathrm{~mW}$ visible collinear laser beam $(633 \mathrm{~nm}$, i.e. red) useful for aiming purposes. The delivered laser power is regulated by the laser source electrical power supply (TDKLambda GEN100-33, 0-100V, 0-33A). As for most light beam exiting an optic fibre, both the 633 and $933 \mathrm{~nm}$ laser beams are highly divergent with a numerical aperture given by the supplier (Lumics $\mathrm{GmbH}$ ) of $0.22 \pm 0.02$, i.e. an half-angle of divergence of $12.7 \pm 1.2^{\circ}$. About $1 \mathrm{~cm}$ after the fibre end, a converging lens of focal $25 \mathrm{~mm}$ (Thorlabs LA1951-B) is thus placed to greatly reduce the divergence of the beam which is almost collinear after the lens. On the laser beam course is then found a diffuser lens. This optical element, also called a Diffractive Optical Element (DOE), is necessary to ameliorate the temperature homogeneity at the sample surface. Indeed the natural beam power shape is nearly a 2D Gaussian curve [30], meaning that the periphery of a disk sample will receive less power than the centre. The DOE employed (Holo/or Ltd., Rehovot, Israel, model RH-217-K-Y-A tailored for our laser wavelength) allows to transform the beam power profile to a round "top-hat" shape [30]. Temperature homogeneity increasing with the use of such DOE is evidenced by Figure 5. Continuing the beam path, a 750-1150 nm broadband dielectric mirror (Thorlabs BB1-E03) is found, set on a 2-axis kinematic mount (Thorlabs KM100). Aside redirecting downward the formerly horizontal beam, the aim of the 
mirror is to finely adjust the sample targeting without moving the other optical elements. The last lens found on the laser beam course is a focusing lens (Thorlabs LA1xxx-B series) whose focal selection will impose the final beam diameter (when it reaches the sample). The focusing lens is placed as close as possible to the sample chamber viewport in order to have a rather large beam at the crossing of the viewport; this is to limit the risks of locally reaching glass-transition or to induce a crack by thermal shocking. Similarly, to avoid having a hot point the beam never reaches a focusing point on its course to the sample. In addition, the sample and its support are filmed by a camera (Toolcraft TO-5139591) to visually control them. To protect the camera from the $933 \mathrm{~nm}$ reflections, an $800 \mathrm{~nm}$ edgepass filter (Thorlabs FES0800) is placed in front of it as well as, when necessary, a broadband light filter (Thorlabs ND series) to avoid saturation effects of the camera. A metallic plate (not represented on Figure 1) is also placed and adjusted to absorb the few $\%$ of direct reflections occurring when the laser beam crosses the viewport. Finally yet importantly, a control \& safety measure is the presence in the L2PAON room of two emergency stop push buttons that, when hit, instantaneously cut down the laser electrical power supply if the operator detects any safety irregularity. Of course as the heating laser is a Class 4 , as per current regulations any laser beam "leak" (partial reflections by optical elements notably) is contained by an in-house built casing (Figure 1) and wearing of suited security glasses (ACAL BFi, T1K16 filters, Evry, France) in the L2PAON room is mandatory when the laser is switched on.

\section{Temperature measurement and regulation.}

Pyrometry. In Figure 1 is depicted a pyrometer. Depending on the experimentation and sample, most notably the range of temperatures to be explored and the sample emissivity characteristics, a different pyrometer (or a duo) should be employed. Table 1 compiles the relevant features or our available pyrometers. All but the Optris are equipped with a weak $633 \mathrm{~nm}$ laser for sample aiming and an integrated lens to focus on small measurement spots. Experimentally the pyrometer does not target directly the sample but a mirror held by a 2-axis kinematic mount that allows moving precisely the target spot along the sample surface notably. For the M308 pyrometer, as the measurement wavelength range $(855-905 \mathrm{~nm})$ is close to the heating laser wavelength $(933 \mathrm{~nm})$, an additional longpass filter was integrated by the manufacturer to mitigate the risk of disrupting the measurements. Accurate measurement of temperature is an essential point for the optimal functioning of the setup and as such it should not be neglected. As a reminder, pyrometers function by measuring a sample radiance. The measured radiance has to be corrected by two important factors: the transmittance $\left(\tau_{\lambda}\right)$ of the media inbetween the sample and the pyrometer (mirrors, viewport and air in our case) and the emissivity $\left(\varepsilon_{\lambda}\right)$ of the sample surface at the pyrometer measurement wavelength $\lambda$ (or range of $\lambda$ ). Both correcting factors are by definition constrained to be $>0$ and $\leq 1$. For $\tau_{\lambda}$, transmissivity by air is considered to be 1 for decimetre range distances. As per the optical elements separating the sample from the pyrometer, the suppliers provide their spectral transmissivity and therefore the $\tau_{\lambda}$ factor entered in the pyrometer is simply the product of the individual transmissivities. Determining the right emissivity for the samples is far more complicated. First because emissivity will depend itself of many parameters, notably crystallinity, surface roughness, porosity, presence of a surface layer (e.g. oxidation scale), impurities effects, and most of all temperature itself. During a temperature ramp, $\varepsilon$ can thus greatly vary directly and/or indirectly (through the evolution of the other influencing parameters by the heat treatment). Fortunately, in practice it exists for every material one or several wavelength range(s) for which emissivity stays almost constant and high whatever non-chemical or non-crystalline modification occurs, at least around a discrete wavelength called the Christiansen point (a $\lambda$ for which $\varepsilon$ is maximal and often $\approx 1$ ), see examples in [31,32]. Therefore to greatly diminish the temperature measurement uncertainties, one should select a pyrometer measuring at a wavelength close the Christiansen point or in a range of stable and high $\varepsilon$ values for the studied material ( $\varepsilon$ values as a function of $\lambda$ to be found in literature data). Practically, this induces the customary rule in pyrometry: "one material $=$ one dedicated 
pyrometer". Even with the greatest care, $\varepsilon$ will be in our experiments the main source of temperature measurement uncertainty. The effect of $\varepsilon$ uncertainty on the temperature measurement error is reported in Table 1 to give an idea of which absolute error should be expected for each pyrometer for a $5 \%$ error on $\varepsilon$ (or $\tau$ ). Comparing the error induced on $\mathrm{T}$ from $\varepsilon$ error between the pyrometers reveals that with increasing $\lambda$, the relative error grows: this is because the error $\Delta \varepsilon / \varepsilon$ is propagated to the $\Delta \mathrm{T} / \mathrm{T}$ error proportionally to $\lambda$. A concrete case of the problematic of pyrometer $\& \varepsilon$ selection is given in the presentation of the application example (end of the present paper).

Table 1. Pyrometers main relevant characteristics.

\begin{tabular}{|c|c|c|c|c|c|c|}
\hline $\begin{array}{l}\text { Brand } \\
\text { Model }\end{array}$ & $\begin{array}{l}\text { Measurement } \\
\text { wavelength(s) }\end{array}$ & $\begin{array}{l}\text { Measurement } \\
\text { range }\left({ }^{\circ} \mathrm{C}\right)\end{array}$ & $\begin{array}{l}\text { Smallest spot } \\
\text { size }(\mathrm{mm})\end{array}$ & $\begin{array}{c}\text { Meas. } \\
\text { accuracy* }\end{array}$ & $\begin{array}{c}\text { Min. error induced } \\
\text { by a } 5 \% \text { error on } \varepsilon \text { or } \\
\tau \text { (at mid-range } T) \dagger\end{array}$ & $\begin{array}{c}\text { Application } \\
\text { example }\end{array}$ \\
\hline $\begin{array}{l}\text { Sensortherm } \\
\text { Metis M308 }\end{array}$ & $0.855-0.905 \mu \mathrm{m}$ & $600-1400$ & 1.5 & $\begin{array}{l} \pm 0.25 \% \\
\text { or } \pm 1^{\circ} \mathrm{C}\end{array}$ & $\begin{array}{c} \pm 0.5 \% \\
\left(\text { at } 1000^{\circ} \mathrm{C}\right)\end{array}$ & $\begin{array}{l}\mathrm{UO}_{2} \text { (this } \\
\text { work) }\end{array}$ \\
\hline $\begin{array}{l}\text { Sensortherm } \\
\text { Metis M322 }\end{array}$ & $\begin{array}{l}\lambda_{1}: 1.65-1.80 \mu \mathrm{m} \\
\lambda_{2}: 1.45-1.65 \mu \mathrm{m}\end{array}$ & $600-2300$ & 0.8 & $\begin{array}{l} \pm 0.3 \% \\
\text { or } \pm 2^{\circ} \mathrm{C}\end{array}$ & $\begin{array}{c} \pm 1.2 \% \\
\left(\text { at } 1450^{\circ} \mathrm{C}\right)\end{array}$ & $\begin{array}{l}\mathrm{B}_{4} \mathrm{C}[15], \\
\text { ceramics }\end{array}$ \\
\hline $\begin{array}{c}\text { Raytek } \\
M M 2 M H V F 1 L\end{array}$ & $1.6 \mu \mathrm{m}$ & $450-2250$ & $<1$ & $\begin{array}{l} \pm 0.3 \% \\
\text { or } \pm 2^{\circ} \mathrm{C}\end{array}$ & $\begin{array}{c} \pm 0.9 \% \\
\left(\text { at } 1350^{\circ} \mathrm{C}\right)\end{array}$ & l \\
\hline $\begin{array}{c}\text { Optris } \\
\text { Csmicro LT22H } \\
* \text { Whichever } \\
\dagger \text { For } \varepsilon=\tau=\end{array}$ & $\begin{array}{l}\quad 8-14 \mu \mathrm{m} \\
\text { is greater } \\
1\end{array}$ & $-50-1030$ & 38 & $\begin{array}{c} \pm 1 \% \text { or } \\
\pm 1{ }^{\circ} \mathrm{C}\end{array}$ & $\begin{array}{c} \pm 4.7 \% \\
\left(\text { at } 490^{\circ} \mathrm{C}\right)\end{array}$ & $\begin{array}{c}\mathrm{Y}_{2} \mathrm{O}_{3}, \mathrm{BN}, \\
\text { metals }\end{array}$ \\
\hline
\end{tabular}

The right pyrometer(s) set in place not only serves to measure the temperature but also to impose the temperature through a Proportional-Integral-Derivative (PID) controller system. We indeed developed a LabVIEW interface program (Figure 1) that allows for the user to display on a same screen and record synchronically pyrometry data, laser power (voltage and amperage imposed by the laser power supply), laser source internal temperature and the status of the emergency stop push buttons. Moreover this LabVIEW interface also allows controlling the heating laser. A manual mode allows the direct commanding of laser power value by entering a voltage value and eventually by programming a voltage ramp. Besides an automatic mode allows transmitting a setpoint value of temperature (given by a chosen pyrometer) to a Programmable Logic Controller (PLC SIEMENS S7-1200) which regulates continuously by an integrated PID the power of the laser, according to this setpoint. The setpoint can also automatically evolve with programmed step (e.g. $+x^{\circ} \mathrm{C}$ increments per $y$ seconds) allowing us to program a thermal cycle. The data exchange between the PLC and the main LabVIEW program is made with an Open Platform Communications (OPC) server. With this servo-system, we can virtually apply any temperature ramp (the laser and its power source being able to withstand an immediate start-up to their maximum powers), reach and maintain a set temperature and program a thermal cycle on the LabVIEW control panel or on the automation touch screen (Figure 2). Both control accesses also warrants the user to set maximum current of the power source to avoid overcompensations in accidental cases such as sample falling down, a suddenly changing $\varepsilon$ following a chemical modification notably or as it already happened an opacification of the viewport glass (from the volatilization of the sample surface and redeposition on the viewport). An example of a $4^{\circ} \mathrm{C} \cdot \mathrm{min}^{-1}$ ramp from $1100^{\circ} \mathrm{C}$ to $1500^{\circ} \mathrm{C}$, is shown in Figure 3. It notably demonstrate the quality of the PID control, which limits overshooting when setting it on (only $+1^{\circ} \mathrm{C}$ in Figure 3 example) and succeed to respect the target temperature with variation below $\pm 2^{\circ} \mathrm{C}$, i.e. the pyrometer guaranteed accuracy (Table 1). At $\sim 5800$ seconds, the sample 
was seen to move laterally a couple mm over few seconds provoking some instability in the temperature measurement: the PID managed to keep the temperature drift below $3^{\circ} \mathrm{C}$ off of the target value (see difference plot in Figure 3). Currently the only safety measure to avoid PID's overcompensations in the case of e.g. the sample falling or suddenly lowering its emissivity (resulting in both cases to a lower temperature pyrometry reading) is to limit the maximum laser power. We intend to implement intelligent safety measures to avoid such problems by e.g. limiting power increase to $0.1 \%$ / PID processing step and having an automatic stopping of the laser if it would need to.

Sample holding and temperature homogeneity. Depending on what is of prime importance, two types of sample holding systems were developed. When one wants the least contacts between the sample holder and the sample, to avoid chemical reactions and/or limit the mass of sample holder material heated to high temperature, we propose to use 3 or 4 tungsten wires of $2-3 \mathrm{~cm}$ long and of $0.5 \mathrm{~mm}$ diameter with the sample side end bevel cut to further reduce surface of contact. The $\mathrm{W}$ wires are themselves supported by a stainless steel support placed on the sample chamber down flange. The first difficulty/default of such sample holding is the important drop in temperature at the samples' periphery because of the natural higher heat loss by radiation of these samples part. This problem can be circumvented for sample ion-implanted in noble gases as a mask can be added at the outer region of the sample (e.g. a $8.3 \mathrm{~mm}$ ring covering the outer $1 \mathrm{~mm}$ of a $\mathrm{UO}_{2}$ pellet sample during ion implantation). When tested with $\mathrm{UO}_{2}$ disks, this kind of sample holding, however, often provoked the fracturing (and fall) of the samples, probably arising from local thermal gradient at the $\mathrm{W}$ tip contact points (since fractures seemed to "connect" two tip positions).

We thus up to now mainly the setup shown in Figure 4. Boron nitride or molybdenum disks are used to support the samples. These are $3 \mathrm{~mm}$ height with a round central cavity of $1 \mathrm{~mm}$ depth and 8.5 $\mathrm{mm}$ diameter. As such they are primarily designed to hold $8.3 \mathrm{~mm}$ diameter $\mathrm{UO}_{2}$ disks (reproducing industrial $\mathrm{UO}_{2}$ fuel pellets diameter). To limit a bit the contact with the sample, these sample holders are grooved ( $\sim .5 \mathrm{~mm}$ depth ridges). The Mo or BN sample holders are themselves supported tungsten cylinders $(\mathrm{h}=2$ to $5 \mathrm{~cm}, \emptyset=0.9 \mathrm{~cm})$.

An important feature of the TDS setup is the possibility to put in the chamber up to 4 samples. This is aimed to avoid regular breaking off the high vacuum state to input new samples. When developing the TDS setup, we checked that heating a sample to high temperatures would not heat up massively the neighbour samples. This was done by a FlexPDE ${ }^{\circledR}$ (from PDE Solutions Inc, Spokane Valley, USA) simulations displayed in Figure 4a. In this simulation, the chamber walls are set at the constant temperature of $20^{\circ} \mathrm{C}$ (water-cooled), while the simulated $\mathrm{UO}_{2}$ sample is set constant at $1000^{\circ} \mathrm{C}$. When a thermal equilibrium is reached, the neighbour sample only heats up to $41^{\circ} \mathrm{C}$, thus stays close to ambient temperatures. This simulation also indicates limited heating of the steel base of the chamber, pointing out the importance of using $\mathrm{W}$ cylinder supports. The results of this simulation were later experimentally confirmed in Figure 4 b. A $\mathrm{B}_{4} \mathrm{C}$ sample was brought at $2000^{\circ} \mathrm{C}$; about 5 seconds after the heating laser was shut off, the photo was taken. The neighbour sample and its Mo support $\sim 2 \mathrm{~cm}$ away were not glowing meaning their temperature was assuredly below $500^{\circ} \mathrm{C}$.

Another objective was to reach thermal homogeneity across the heated sample (while limiting the volume and temperature of sample supports). This was studied with new simulations presented in Figure 5. Figures 5a and b present the simulation setup: $\mathrm{UO}_{2}$ disk deposited on a Mo support itself placed on a $\mathrm{W}$ cylinder. The $8.3 \mathrm{~mm}$ diameter $\mathrm{UO}_{2}$ sample and surrounding Mo are illuminated by a quasi top-hat power profile round laser (homogeneous power for $\mathrm{r}-1 \mathrm{~mm}$ centre zone, and a max to zero transition outer ring of $1 \mathrm{~mm}$ large, see Figure 5c dotted power profiles). The diameter of the heating laser spot is 
varied from $10 \mathrm{~mm}$ (radius $\mathrm{r}=5 \mathrm{~mm}$ with homogeneous power in the inner $4 \mathrm{~mm}$ only, meaning in this case that the Mo support receives very limited laser power) to $18 \mathrm{~mm}$ (i.e. all the $\mathrm{UO}_{2}$ and Mo surface receive an homogeneous laser heating). The total laser power is adjusted so that the centre of the $\mathrm{UO}_{2}$ top surface is at $1000^{\circ} \mathrm{C}$ when thermal equilibrium is reached. It is confirmed that the $\mathrm{W}$ cylinder mitigates well the temperature along its height allowing to greatly limit the temperature of chamber steel base and down flange. When the $10 \mathrm{~mm}$ diameter is selected (red curve in Figure 5c), an important drop of the temperature is observed for the outer millimetre of the sample, down to $890^{\circ} \mathrm{C}$. Although this allows having a Mo maximum temperature of only $745^{\circ} \mathrm{C}$, such a high temperature difference across the $\mathrm{UO}_{2}$ sample disqualifies using such a narrow laser spot. Increasing only by $2 \mathrm{~mm}$ the laser diameter (orange curve in Figure 5c) allows to greatly reduce the above-mentioned problem since the outer $\mathrm{UO}_{2}$ is now expected to be only $20^{\circ} \mathrm{C}$ cooler than the centre, while at the same time the Mo is at a maximum temperature of $890^{\circ} \mathrm{C}$. Again increasing now to $14 \mathrm{~mm}$ the diameter of the laser is expected to limit to $13^{\circ} \mathrm{C}$ the temperature decrease across the sample surface while having the Mo kept under $930^{\circ} \mathrm{C}$ (green curves). Increasing further the laser diameter is found to continue having a higher Mo temperature but without greatly increasing sample temperature homogeneity.

This was later checked by experimentally realizing the exact same system and measuring by pyrometry the $\mathrm{UO}_{2}$ surface temperature across the sample. The focal lens was selected to reach a 633 $\mathrm{nm}$ aiming beam of $\sim 12 \mathrm{~mm} \emptyset$. This measurement is imperfect because of 1 ) the difficulty to perfectly centre the laser beam (characterized by the spanning of temperatures for a same radial position, i.e. vertical error bars), 2) the difficulty to place the pyrometer aiming at a precise and constant distance from the sample centre and 3 ) the pyrometers spot sizes ( 0.8 and $1.5 \mathrm{~mm}$ respectively), the two latter explaining the horizontal error bars. It, however, confirms the trend shown by the simulation and the necessity to have an heating laser spot larger than the sample. Besides, one has to remind that the 633 $\mathrm{nm}$ (aiming, visible) and $933 \mathrm{~nm}$ (heating, infrared) will not behave exactly in the same manner, especially when passing through the DOE (tailored for the $933 \mathrm{~nm}$ wavelength). Since the measured temperature homogeneity is lower than the simulated one, it is thus likely that the $933 \mathrm{~nm}$ laser beam is actually smaller than the visible $633 \mathrm{~nm}$ one when landing on the sample. Therefore we conclude from this study that targeting a $12-14 \mathrm{~mm}$ diameter spot for the $633 \mathrm{~nm}$ red aiming laser is preferable to reach a satisfying sample surface homogeneity $\left(20^{\circ} \mathrm{C}\right.$ or less at $1000^{\circ} \mathrm{C}$, i.e. of the same range as the pyrometry measurement error, see the application example later in this document), while limiting the heating of support elements. 


\section{UHV SETUP AND GAS TREATMENT}

Figure 2 shows the UHV parts of the L2PAON setup. The UHV is constituted by individual "volumes" (labelled V in Figure 2) that are separated by UHV valves, either Swagelok SS-4H-TW (Solon, Ohio) or VACGEN All-Metal DN19CF (Hailsham, UK). All volumes were measured with a pressure gauge (INFICON AG Li-9496 Balzers CDG025D-S, accuracy $\leq 0.25 \%$ for the pressure range used) and using the ideal gas law stating that for a constant $\mathrm{T}$,

$$
\begin{aligned}
& P_{a} V_{a}=P_{a, b}\left(V_{a}+V_{b}\right) \\
& \text { or } V_{b}=\frac{P_{a} V_{a}-P_{a, b} V_{a}}{P_{a, b}}
\end{aligned}
$$

with $\mathrm{V}_{\mathrm{a}}$ a previously precisely calibrated reference volume in which few mbar of air are inserted at a measured pressure $\mathrm{P}_{\mathrm{a}}, \mathrm{V}_{\mathrm{b}}$ the volume to be determined, and $\mathrm{P}_{\mathrm{a}, \mathrm{b}}$ the pressure read by the gauge once the valve separating the volumes $\mathrm{A}$ and $\mathrm{B}$ had been opened for few tens seconds (provided that $\mathrm{B}$ was previously under UHV conditions, thus $\mathrm{P}_{\mathrm{b}}$ considered null. With this approach, all relevant volumes were determined (reported in Table 2).

Table 2. Volumes (V) characteristics.

Label (see Figure 2)

Volume $\left(\mathrm{cm}^{3}\right)$ and error

Nature, usefulness, functioning temperature(s)

\begin{tabular}{ccc}
\hline V7 & $1534 \pm 10$ & Sample chamber, room temperature to $>2000^{\circ} \mathrm{C}$ \\
\hline V6 & $408.76 \pm 0.35$ & $\begin{array}{c}\text { Central volume, } \\
\text { access to accessories and pumping units }\end{array}$ \\
\hline V5 & $0.8976 \pm 0.00030$ &
\end{tabular}

\begin{tabular}{cc}
\hline V5 & $0.8976 \pm 0.00030$ \\
\hline V4 & $25.99 \pm 0.12$ \\
\hline V3* & $90.48 \pm 0.54$ \\
\hline V2 & $0.612 \pm 0.013$ \\
\hline V1 & $12.41 \pm 0.19$ \\
\hline V0 & $195 \pm 2$ \\
\hline
\end{tabular}

Line of volumes connecting to the MS line (junction at V0) and allowing to realize various ranges of sampling and gas

\begin{tabular}{|c|c|c|}
\hline $\mathrm{Vc}$ & $43.12 \pm 0.14$ & $\begin{array}{l}\text { Active charcoal (high specific surface area) for trapping by cryogenic } \\
\text { physi-sorption and separation of noble gases, }-196 \text { to } 150^{\circ} \mathrm{C}\end{array}$ \\
\hline $\mathrm{Vg}$ & $31 \pm 3$ & Getter: Ti sponge for chemical trapping of active species, $300-700^{\circ} \mathrm{C}$ \\
\hline $\mathrm{Vm}$ & $987.66 \pm 0.42$ & Oxygen reservoir \\
\hline $\mathrm{Vn}$ & $0.634 \pm 0.006$ & Small volume for oxygen sampling from $\mathrm{Vm}$ \\
\hline Vo & $62.45 \pm 0.72$ & Oxygen gauge, $650-750^{\circ} \mathrm{C}$ \\
\hline $\mathrm{Vp}$ & $169.53 \pm 0.44$ & Secondary sample chamber, room temperature to $>2000^{\circ} \mathrm{C}$ \\
\hline Vs & $147.18 \pm 0.14$ & Sorb-AC: chemical trapping of active species \\
\hline $\mathrm{Vt}^{*}$ & $29.19 \pm 0.29$ & $\mathrm{~W}$ powder, $\mathrm{O}_{2}$ trapping in gas sampling destined for MS, $750^{\circ} \mathrm{C}$ \\
\hline Vw & \multirow{3}{*}{$16.84 \pm 0.16$} & \multirow{4}{*}{$\begin{array}{l}\text { Sampling volumes, } \\
\text { useful for rapid kinetics (minutes range) }\end{array}$} \\
\hline $\mathrm{Vx}$ & & \\
\hline $\mathrm{Vy}$ & & \\
\hline $\mathrm{Vz}$ & $48.00 \pm 0.48$ & \\
\hline
\end{tabular}
fractionations. 
The features of the UHV setup is here described. After one or several samples are inserted in the samples chambers, UHV pumping is performed in all the volumes likely to be employed. A primary pump (Edwards nXDS10iR, Burgess Hill, UK), a turbomolecular pump (Oerlikon Leybold Vacuum TurboVac 151, Cologne, Germany) coupled with the primary pump, then finally a ionic pump (Vinci Technologies Meca2000 PID 50N, Nanterre, France), all accessible from the V6 volume are used in the presented order to reach a usual final vacuum down to $10^{-9}-10^{-10}$ mbar.

For a TDS experiment, the gases are evolved from the heated sample, indifferently from V7 or Vp sample chambers (Figure 2). The gases are at least let to expand to the V6 volume where they can undergo various treatments depending on what valves are chosen to be opened. Samplings for MS measurements can be done with various approaches anticipated during the L2PAON conception:

_ For relatively slow-release kinetics, V0 to V5 volumes are designed to be used for sampling. Depending on the noble gases quantities released by the studied sample, different sampling volumes can be considered. For example, tiny samplings such as V5 $(\mathrm{V} 5 /(\mathrm{V} 5+\mathrm{V} 6+\mathrm{V} 7)=0.046 \%)$ can be selected when high quantities (relatively to the MS sensitivity) of noble gases are released. In this case the sequence of actions is the following: 1) start at time $t_{0}$ of the TDS experiment with the sample chamber opened to the V6 and V5 volumes, 2) sampling $s_{1}$ at time $t_{1}$ by closing the valve between $V 5$ and $V 6,3$ ) free expansion of $s_{1}$ up to the MS entry volume, passing along SORB-AC and getter traps (of the PIAGARA platform), with an eventual addition of a mono-isotopic reference spike to improve quantification precision 4) closing of the MS entry valve and free expansion in the MS volume of a fraction $\mathrm{s}_{1}, 5$ ) analysis by MS + pumping with the turbomolecular pump accessible from V0 of the unused part of $\mathrm{s}_{1}$ and 6) pumping of the MS + closing of the valve between V5 and V4 followed by the reopening of the V5-V6 valve to prepare the following $\mathrm{s}_{2}$ sampling to be made at $\mathrm{t}_{2}$. The sampling quantity can be adapted to meet MS optimal range of analysis $\left(10^{8}\right.$ to few $10^{10}$ atoms of each analysed isotope) by taking one or several larger volumes in the V0 to V6 series, or at the opposite can be further decreased by fractioning the sampling: e.g. the V5/(V5+V6+V7) sampling $(0.046 \%)$ is expanded in $\mathrm{V} 2+\mathrm{V} 3+\mathrm{V} 4+\mathrm{V} 5$ and only the $\mathrm{V} 2 /(\mathrm{V} 2+\mathrm{V} 3+\mathrm{V} 4+\mathrm{V} 5)$ fraction $(0.52 \%)$ is let to access the MS entry volume, leading relatively simply to a $2.40 \pm 0.1210^{-4} \%$ fraction. A whole sequence between two samplings (i.e. between $s_{1}$ and $s_{2}$ ) takes a minimum of 15 minutes, limiting to this duration the time resolution.

_ However for rapid gas desorption kinetics where e.g. 5 min sampling frequency is required, a "sampling queue" can be realized by doing the heat treatment with the dedicated Vw, Vx, Vy, Vz volumes opened. When a sampling has to be done, a fraction of the released gas can be trapped by closing the valve allowing to isolate such volume and therefore preserve the gas for a MS analysis realized after the end of the TDS treatment (i.e. the sample heating). If needed, the series of volumes V6 to $\mathrm{V} 0$ can also be used to increase the number of queue slots.

_ A last possibility to work with a minimal time interval between two MS measurements is to perform the TDS experiments with all valves separating the sample chamber to the MS opened. This riskier configuration can only be employed for experiments with $\mathrm{He}$ or Ne. Indeed it is necessary to set along the gas path active charcoal powders brought down to liquid $\mathrm{N}_{2}$ temperature $(96 \mathrm{~K})$. At this temperature all gaseous atoms or molecules excluding $\mathrm{He}$ and $\mathrm{Ne}$ but including the heavier noble gases gets dynamically trapped on the surfaces of this high specific area material. These highly efficient traps avoid that species such as oxygen reaches the MS source, where it will potentially disrupt the measurement or worst destroy the source filament. For such experiment the active charcoal in the volume Vc is, of course, employed as well as a second one set in a volume replacing V3+Vt on Figure 2. With this setup configuration MS spectra can be recorded at few tens of second intervals only. This particular configuration is detailed further in our previous paper [15]. 
The role and usefulness of the Figure 2's volumes unmentioned before are hereafter presented:

_ Ti powder (supplier, purity) getter (Vg) and the SORB-AC (SAES Getter, Italy) (Vs) traps can be opened to the sample gas during TDS experiment, notably when important release of chemically active gases are expected, as a way to pre-purify the desorbed gas before sampling and thus preserve the cleanliness of the rest of the PIAGARA platform.

_ In Figure $2 \mathrm{Vm}, \mathrm{Vn}$ and $\mathrm{Vo}$ are objects only employed when working with additions of $\mathrm{O}_{2}$ such as the case example presented in this report. In the $\sim 1000 \mathrm{~cm}^{3} \mathrm{Vm}$ reservoir $1.052 \mathrm{mbar}$ of $\mathrm{O}_{2}$ was initially inserted from a commercial analytical grade oxygen source (ALPHAGAZ ${ }^{\mathrm{TM}} 1,>99.995 \%$ pure 200 bars $\mathrm{O}_{2}$, Air Liquide, France). This initial pressure is, of course, recalculated each time a $\mathrm{Vn}\left(\sim 0.6 \mathrm{~cm}^{3}\right)$ or $\mathrm{V} 4+\mathrm{Vn}\left(\sim 26.6 \mathrm{~cm}^{3}\right)$ sampling is drawn off. With this system we are able to punctually add adjusted $\mathrm{O}_{2}$ pressures up to few $\sim 10^{-5} \mathrm{mbar}$ in the $\mathrm{V} 7$ sample chamber. As used for the application example presented here, this setup notably allows performing stepwise increases of the oxygen pressure over the heated sample. Vo hosts a probe (MicroPoas ${ }^{\circledR}$, SETNAG, France) measuring $\mathrm{O}_{2}$ partial pressure $\left(\mathrm{pO}_{2}\right)$ using Nernst law and $\mathrm{O}$ ions migrating properties in $\mathrm{ZrO}_{2}$ at $\mathrm{T}>600^{\circ} \mathrm{C}$. The probe functions correctly for total pressures from $10^{-5}$ mbar and can thus give meaningful measurements only for the higher end of the actual experimental $\mathrm{O}_{2}$ pressure range. 


\section{AN APPLICATION EXAMPLE: EFFECT OF OXYGEN ON KR DIFFUSION IN UO ${ }_{2 \pm X}$}

Xenon and krypton are produced in $\mathrm{UO}_{2}$ nuclear fuels by uranium (and plutonium) fission. Contrary to almost all other fission products, they are not soluble in the fuel and get either trapped in defect agglomerates, in gaseous fission products bubbles, or diffuse out of the fuel [16]. These phenomena have important repercussions on the fuel behaviour, notably by diminishing its thermal conductivity thus the global energetic performance. Therefore, from the advent of nuclear reactors numerous works have been devoted to the study of $\mathrm{Xe}$ and $\mathrm{Kr}$ diffusion kinetics and mechanisms in $\mathrm{UO}_{2}$ [23,33-37]. In particular it was determined that deviations (even down to $10^{-4}$ [38,39]) of the stoichiometry of $\mathrm{UO}_{2}$, either positive $(\mathrm{O} / \mathrm{U}>2)$ or negative $(\mathrm{O} / \mathrm{U}<2)$ has profound influence on fission gases diffusion mechanisms and consequently on their diffusion kinetics as well [38-40]. Since $\mathrm{UO}_{2}$ stoichiometry could change during normal use, and would assuredly do so in incidental or accidental conditions, it is of prime importance to investigate $\mathrm{O} / \mathrm{U}$ ratio effects on $\mathrm{Xe}$ and $\mathrm{Kr}$ diffusion in $\mathrm{UO}_{2}$.

We have been working on the subject of noble gases diffusion for a decade using a conventional resistive furnace $[13,14,16,41]$, however, investigating $\mathrm{UO}_{2}$ stoichiometry deviations was out of the question because the hot and large Mo furnace surface would act as a buffer for $\mathrm{O}_{2}$ potential, rendering impossible any attempt to modify the $\mathrm{UO}_{2}$ sample stoichiometry by e.g. $\mathrm{O}_{2}$ additions. Having now at our disposal a quasi-cold environment for $\mathrm{UO}_{2}$ annealing, it is conceivable to modify $\mathrm{UO}_{2}$ stoichiometry during a TDS experiment.

Figure 6 below present the results of a TDS experiment on a $\mathrm{UO}_{2}$ at $1300^{\circ} \mathrm{C}$ with successive $\mathrm{O}_{2}$ additions. The sample employed in this experiment is a polycrystalline $\mathrm{UO}_{2 \pm \mathrm{x}}$ disk $(-0.001<\mathrm{x}<0.001)$ implanted with $5.10^{+13}{ }^{83} \mathrm{Kr}_{\mathrm{cm}}{ }^{-2}$ at $2 \mathrm{MeV}$, prepared with the same protocol as that described in [16] (with O-PU surface treatment). According to SRIM 2013 simulations [42], the $\mathrm{Kr}$ atoms are implanted in a range of depth of 0 to $1.2 \mu \mathrm{m}$ with this $2 \mathrm{MeV}$ energy. The sample was placed in the chamber V7 (Figure 2) on a Mo crucible (as seen in Figure 4), with the Kr-implanted face upwards. The L2PAON setup was pumped overnight down to $10^{-9}$ mbar. Using the $633 \mathrm{~nm}$ laser aim, the beam course was centred and adjusted to illuminate the whole sample surface plus an extra $\sim 2 \mathrm{~mm}$ to ameliorate temperature homogeneity across the sample, as discussed with Figure 5. Preparatory experiments showed that the Mo support part directly surrounding the sample equilibrates at a maximum temperature of only $\sim 1200^{\circ} \mathrm{C}$ in this configuration. As the Ti getter $(\mathrm{Vg})$ and the Sorb-AC (Vs) traps are designed to catch oxygen, they were isolated before the start of the experiment. Since it incidentally traps oxygen traces, the volume containing the $\mathrm{O}_{2}$ gauge (Vo) was also closed. Therefore, the initial work volume (where the emitted $\mathrm{Kr}$ would expand to) was the V0-V7 volume line only.

At the time $\mathrm{t}=0$, the laser was switched on and progressively manually increased to bring the sample up to $1300^{\circ} \mathrm{C}$ in less than 2 minutes, which is negligible compared to an usual TDS experiment on $\mathrm{UO}_{2}$ (several hours). The PID was then let to manage the temperature stabilization at $1300^{\circ} \mathrm{C}$, which was kept under $\pm 1^{\circ} \mathrm{C}$ variations during the experiment duration. The Metis M308 pyrometer (Table 1) was selected for this experiment, targeting with a 2-3 $\mathrm{mm}$ spot size the sample centre. A constant emissivity value of 0.85 was chosen, as advisable from refs. [43,44], since very limited $\varepsilon$ shifts are expected in our experimental conditions $\left(1300^{\circ} \mathrm{C}\right.$, varying $\mathrm{UO}_{2 \pm x}$ stoichiometry). Considering as recommended by Fink [44] to apply a \pm 0.05 uncertainty on the $\varepsilon=0.85$ value for $\mathrm{UO}_{2 \pm \mathrm{x}}$, the considered pyrometry error at $1300^{\circ} \mathrm{C}$ is then $8^{\circ} \mathrm{C}$ (thus $\pm 0.6 \%$ ). Integrating other sources of errors (pyrometer accuracy, accuracy of optical elements transmissivity values notably), a maximum error of $\pm 15^{\circ} \mathrm{C}$ is considered. 
Down to every 20 min we realized gas samplings, e.g. by closing the valve between V4 and V5. The sampled gas was immediately let to expand to $\mathrm{Vt}$ where a $750^{\circ} \mathrm{C}$ tungsten powder allows to trap within minutes any oxygen present. A fraction of the treated sampling was then let to expand up to the MS entry volumes, passing along getters and a Sorb-AC trap, and was mixed with a precisely calibrated

${ }^{83} \mathrm{Kr}$ spike. Once being analysed by MS, the turbo-molecular pump accessible by a valve at the V0 volume (Figure 2) was used to pump out the unused fraction of the sampling. Few minutes later, this same valve was closed and the one separating V4 and V5 was reopened letting the possibility after a couple minutes to do a new sampling. Since the heating and cooling of the $\mathrm{UO}_{2}$ sample between nearambient temperatures and $1300^{\circ} \mathrm{C}$ can be done in a matter of seconds and since the kinetics we are working on rather requires hours long experiment, it was possible, when needed, to work in a "stop and go" manner. The experiment reported in Figure 5 was as such realized along 6 days, with stops performed at the ends of annealings $(A)$ only.

After an initial $3 \mathrm{~h}$ annealing ( $A l$ in Figure 6), 7 successive and increasing oxygen additions were made (at the beginning of $A 2-A 8$ ), with increasing $\mathrm{O}_{2}$ quantities (Table 3 ). At the end of $A 8$, the sample was rapidly cooled down to room temperature (laser heating stopped) and the valve isolating $\mathrm{Vo}$ (the $\mathrm{O}_{2}$ gauge) was opened. No residual oxygen was detected, indicating that the vast majority of the oxygen had been assimilated by the $\mathrm{UO}_{2}$ sample (and possibly the Mo support). Oxygen intake by the $\mathrm{UO}_{2}$ sample was confirmed by the correlated increases in $\mathrm{Kr}$ release rates each time a new $\mathrm{O}_{2}$ addition was made (Figure 6 and Table 3). $A 9$ was done after a night of $\mathrm{UHV}$ pumping and without a new $\mathrm{O}_{2}$ addition. The fact that the same $\mathrm{Kr}$ release trend (Figure 6) and kinetics (Table 3) are observed for A8 and A9 indicates that the $\mathrm{UO}_{2}$ sample either retained the newly adopted $\mathrm{O} / \mathrm{U}$ ratio and/or kept the structural changes brought by the former oxygen addition (see discussion hereafter).

Table 3. Apparent $\mathrm{Kr}$ diffusion rate coefficients in $\mathrm{UO}_{2 \pm x}$ as a function of the $\mathrm{O}_{2}$ additions. The diffusion rates were determined using the model described in [16,52].

\begin{tabular}{|c|c|c|c|c|c|}
\hline $\begin{array}{l}\text { Annealing } \\
\text { label (see } \\
\text { Figure) }\end{array}$ & $\begin{array}{c}\text { Sampled } \\
\qquad \mathrm{O}_{2} \\
\text { volume }\end{array}$ & $\begin{array}{l}\text { Added fraction of } \\
\text { sampled } \mathrm{O}_{2}\end{array}$ & $\begin{array}{c}\text { Cumulated } \\
\text { O additions } \\
(\mathrm{mol})\end{array}$ & $\begin{array}{c}\text { Theoretical max. } \\
\text { increase of } x \\
\text { (cumulated) }\end{array}$ & $\begin{array}{l}\text { Apparent diffusion } \\
\text { rate coefficient } \\
\left(\mathrm{x} 10^{-20} \mathrm{~m}^{2} \cdot \mathrm{s}^{-1}\right)\end{array}$ \\
\hline Al & None & N/A & 0 & 0 & $13.42 \pm 0.77$ \\
\hline$A 2$ & \multirow{4}{*}{$\mathrm{Vn}$} & $\mathrm{Vn} /(\mathrm{V} 4+\mathrm{V} 5+\mathrm{Vn})$ & $6.2 \times 10^{-10}$ & $2.6 \times 10^{-7}$ & $15.97 \pm 0.47$ \\
\hline$A 3$ & & $\mathrm{~V} 4$ / (V1+V2+V3+V4+Vn) & $5.4 \times 10^{-9}$ & $2.5 \times 10^{-6}$ & $26.18 \pm 0.73$ \\
\hline A4 & & $\begin{array}{c}(\mathrm{V} 1+\mathrm{V} 2+\mathrm{V} 3+\mathrm{V} 4+\mathrm{V} 5) / \\
(\mathrm{V} 0+\mathrm{V} 1+\mathrm{V} 2+\mathrm{V} 3+\mathrm{V} 4+\mathrm{V} 5+\mathrm{V} 6+\mathrm{Vn})\end{array}$ & $1.7 \times 10^{-8}$ & $7.6 \times 10^{-6}$ & $23.9 \pm 1.2$ \\
\hline$A 5$ & & all of $\mathrm{Vn}$ & $4.4 \times 10^{-8}$ & $1.9 \times 10^{-5}$ & $38.18 \pm 0.81$ \\
\hline$\overline{A 6}$ & \multirow{3}{*}{ V4 } & $\mathrm{V} 4 /(\mathrm{V} 0+\mathrm{V} 1+\mathrm{V} 2+\mathrm{V} 3+\mathrm{V} 4)$ & $1.3 \times 10^{-7}$ & $5.5 \times 10^{-5}$ & $54.8 \pm 2.9$ \\
\hline$A 7$ & & $\mathrm{~V} 4 /(\mathrm{V} 1+\mathrm{V} 2+\mathrm{V} 3+\mathrm{V} 4)$ & $3.3 \times 10^{-7}$ & $1.4 \times 10^{-4}$ & $71.1 \pm 2.5$ \\
\hline$A 8$ & & all of V4 & $1.3 \times 10^{-6}$ & $5.7 \times 10^{-4}$ & $185.0 \pm 3.9$ \\
\hline$A 9$ & None & N/A & N/A & $5.7 \times 10^{-4}$ & $175.7 \pm 7.6$ \\
\hline
\end{tabular}

For $A 3$, for which a maximum increase of $\mathrm{x}$ in $\mathrm{UO}_{2+\mathrm{x}}$ is only $2.5 \mathrm{x} 10^{-6}$, an effect on $\mathrm{Kr}$ release rates thus diffusion kinetics is already clearly detectable. Such a high influence of $\mathrm{x}$ on the apparent diffusion rate $D$ is, however, dubious according to literature data [24-26,45] since an increase of one order of magnitude of $D$ is expected for an x increase of the order of $10^{-2}$. Further work is required to investigate on this matter, but we already suspect either 1) an inhomogeneous intake of oxygen by the 
$\mathrm{UO}_{2}$ pellet resulting in a higher $\mathrm{x}$ increase at the subsurface, i.e. where the $\mathrm{Kr}$ is implanted and/or 2) an interaction of the added oxygen with the structural defects produced along $\mathrm{Kr}$ ion implantation

[16,46-51]: if oxygen intake and diffusion by and through the implanted $\mathrm{UO}_{2}$ surface promotes defects annihilation, then an acceleration in the apparent diffusion rate of $\mathrm{Kr}$ is indeed expected [16].

\section{SUMMARY}

A new TDS setup, dedicated to the study of noble gases diffusion in materials, but transposable to any TDS applications, is introduced. Its main feature is to be based on a localised laser heating. As such it presents the following advantages \& capabilities:

_ Reducing atmospheric and memory effects contamination (cold UHV walls)

- Sample temperature from room temperature to over $2000^{\circ} \mathrm{C}$ while working in a relatively "cold" environment, allowing to have several other samples awaiting in the main UHV chamber.

_ Extended controls of sample heating (through a PID) allowing applying through a LabVIEW interface controlled heating and cooling ramps and plateaus.

_ Sample support design and Gaussian to Top-hat transformation of the laser heating beam allows to reduce sample temperature heterogeneity while keeping at minimum heated materials volumes and temperatures (aside the sample, obviously)

_ Possibility to input during TDS reactive gases (see application example)

Coupled to our mass spectrometry platform, noble gas TDS down to a detection limit of $10^{7}$ atoms of a given noble gas isotopes can thus be performed.

\section{AKNOWLEDGEMENTS}

The L2PAON setup was mainly funded by the Bordeaux university IDEX grant "Chaire d'Installation" awarded to D.H. Secondary funding was brought through the CEA-CNRS NEEDS collaborative contracts projects "MATABS" and "TRANSCOMB" and through direct CNRS/IN2P3 and CEA funding. Later development and the $\mathrm{UO}_{2}$ experiment were done with the funding from the Euratom research and training programme 2014 - 2018 through the INSPYRE project under grant agreement No 754329. This research contributes to the Joint Programme on Nuclear Materials (JPNM) of the European Energy Research Alliance (EERA), in the specific framework of the COMBATFUEL Project.

\section{AUTHORS DECLARATIONS}

Conflicts of interest. The authors have no conflicts to disclose.

Data availability statement. The data that support the findings of this study are available from the corresponding author upon reasonable request. 
Figure 1. Diagram of the L2PAON laser heating setup.

Figure 2. Schematic of the L2PAON UHV components. Some descriptions of the volumes V are given in Table 2.

Figure 3. Example of a heat treatment for a $\mathrm{B}_{4} \mathrm{C}$ sample (2 fragments). In red (fine line) is the programmed temperature to be attained by the PID, in orange (squares) is the actual measured temperature and in purple with a reduced ordinate scale is the difference between the two temperatures. All signals are time-synchronized in the LabVIEW program. The M322 pyrometer was used (Table 1); it targets the centre of one coupon as evidenced by its $633 \mathrm{~nm}$ aiming laser spot seen in the photo taken at $1200^{\circ} \mathrm{C}$ (brighter spot, $\sim 1 \mathrm{~mm}^{2}$ spot size, $\varepsilon=0.85[15]$ ). The heating up to $\sim 1095^{\circ} \mathrm{C}$ is manually undertaken in under 3 minutes, then the PID is let to control the laser power to stabilize the temperature at $1100^{\circ} \mathrm{C}$, which it does in a matter of seconds. The $4^{\circ} \mathrm{C} / \mathrm{min}$ heating ramp $\left(0.2^{\circ} \mathrm{C} / 3 \mathrm{sec}\right.$ steps $)$ is then set.

Figure 4. a) Thermal simulation done with FlexPDE of an experimental setup. All objects are initially set at $20^{\circ} \mathrm{C}$ except the left $\mathrm{UO}_{2}$ sample set constant at $1000^{\circ} \mathrm{C}$. Temperature of the chamber walls and of the $1000^{\circ} \mathrm{C}$ sample are fixed to remain constant while the other elements are let to equilibrate. The darker the color the higher the temperature. b) Photo of a $\mathrm{B}_{4} \mathrm{C}$ fragment disposed on a Mo sample holder seconds after cutting off the heating laser (sample initially at $2000^{\circ} \mathrm{C}$ ). The second sample holder present $\sim 2 \mathrm{~cm}$ away only heats up to $\sim 60^{\circ} \mathrm{C}$ according to the thermal simulation $\left(41^{\circ} \mathrm{C}\right.$ max for the $\mathrm{UO}_{2}$ sample). The Mo sample holders diameters are $16 \mathrm{~mm}$ and can be used by the readers as a scale bar.

Figure 5. Results of thermal simulations (FlexPDE) realized to determine the optimal heating laser beam diameter. Representation in a) and its close-up cross-section in b) were done with a beam diameter of $14 \mathrm{~mm}$ (green curves in c)). Simulated quasi top-hat power profile for the heating laser are given as dotted lines in c) (referring to the right ordinate axis). In c) the plain curves are temperature line profiles across the $\mathrm{UO}_{2}$ and Mo exposed up surface (green segments in b)). Comparison with experimental measurements was done using both M322 and M308 pyrometers and adjusting the aiming laser spot size to approximately $12 \mathrm{~mm}$.

Figure 6. Cumulated releases of krypton as a function of $1300^{\circ} \mathrm{C}$ annealing time, quantified by mass spectrometry (black triangles). The orange line is the result of the application of a continuum model described in [16,52]. Blue steps, referring to the right-side axes informs on the oxygen additions. Blue ticks on the experimental $\mathrm{Kr}$ release points aim at pointing when oxygen additions are made. 
[1] Z. Silvestri, S. Azouigui, S. Bouhtiyya, S. Macé, M.D. Plimmer, P. Pinot, F. Tayeb-Chandoul, R. Hannachi, Thermal desorption mass spectrometer for mass metrology, Rev. Sci. Instr. 85 (2014) 045111. doi: $10.1063 / 1.4870921$

[2] S. Stuckenholz, C. Büchner, H. Ronneburg, G. Thielsch, M. Heyde, H.-J. Freund, Apparatus for low temperature thermal desorption spectroscopy of portable samples, Rev. Sci. Instr. 87 (2016) 045103. doi: $10.1063 / 1.4945265$

[3] T. Hanna, H. Hiramatsu, I. Sakaguchi, H. Hosono, Highly hydrogen-sensitive thermal desorption spectroscopy system for quantitative analysis of low hydrogen concentration $\left(\sim 1 \times 10^{16}\right.$ atoms $/ \mathrm{cm}^{3}$ ) in thin-film samples, Rev. Sci. Instr. 88 (2017) 053103. doi: 10.1063/1.1147216

[4] D.S. Choi, J.H. Han, N.G. Park, K.S. Kim, C.N. Whang, New method for thermal desorption spectroscopy using field electron emission microscopy, Rev. Sci. Instr. 67 (1996) 2573. doi: $10.1063 / 1.1147216$

[5] T.P. Huijgen, W.H.B Hoondert, L.J. Seijbel, B.J. Thijsse, A. van den Beuke, An apparatus for combined ion-beam assisted deposition and thermal desorption spectrometry, Nucl. Instr. Meth. B59-B60 (1991) 150-154. doi: 10.1016/0168-583X(91)95196-K

[6] A.A. Rusinov, Y.M. Gasparyan, S.F. Perelygin, A.A. Pisarev, S.O. Stepanov, N.N. Trifonov, A setup for thermodesorption measurements, Inst. Exp. Tech. 52 (2009) 871-876. doi: $10.1134 /$ S0020441209060219

[7] A. Soleimani Dorcheh, D. Denysenko, D. Volkmer, W. Donner, M. Hirscher Noble gases and microporous frameworks; from interaction to application, Microporous Mesoporous Mater. 162 (2012) 64-68. doi: 10.1016/j.micromeso.2012.06.004

[8] E. V. Kornelsen, The interaction of injected helium with lattice defects in a tungsten crystal, Radiation Effects 13 (1972) 227-236. doi: 10.1080/00337577208231184

[9] Z. Fu, N. Yoshida, H. Iwakiri, Z. Xu, Thermal desorption and surface modification of He+ implanted into tungsten, J. Nucl. Mater. 329-333 (2004) 692-696. doi: 10.1016/j.jnucmat.2004.04.190

[10] E.D. Marenkov, V. Tsvetkov, A.A. Pisarev, Y.M. Gasparyan, A.A. Rusinov, Deuterium release from pores in tungsten created by $10 \mathrm{keV}$ D3+ beam, Nucl. Instr. Meth. B269 (2011) 876-880. doi: 10.1016/j.nimb.2010.12.049

[11] L.J. Seijbel, W.H.B Hoondert, T.P. Huijgen, B.J. Thijsse, A. van Veen, A. van den Beuke, Defects in nonstoichiometric TiC studied by TDS, Nucl. Instr. Meth. B59-B60 (1991) 1336-1339. doi: 10.1016/0168-583X(91) $95825-\mathrm{X}$

[12] F. Linez, E. Gilabert, A. Debelle, P. Desgardin, M.-F. Barthe, Helium interaction with vacancytype defects created in silicon carbide single crystal, J. Nucl. Mater. 436 (2013) 150-157. doi: 10.1016/j.jnucmat.2013.01.288.

[13] Z. Talip, T. Wiss, E.-A. Maugeri, J.-Y. Colle, P.-E. Raison, E. Gilabert, M. Ernstberger, D. Staicu, R.J.M. Konings, Helium behaviour in stoichiometric and hyper-stoichiometric $\mathrm{UO}_{2}$, J. Eur. Ceram. Soc. 34 (2014) 1265-1277. doi: 10.1016/j.jeurceramsoc.2013.11.032

[14] P. Garcia, E. Gilabert, G. Martin, G. Carlot, C. Sabathier, T. Sauvage, P. Desgardin, M.-F. Barthe, Helium behavior in $\mathrm{UO}_{2}$ through low fluence ion implantation studies, Nucl. Instr. Meth. B327 (2014) 113-116. doi: 10.1016/j.nimb.2013.11.042 
[15] D. Horlait, D. Gosset, A. Jankowiak, V. Motte, N. Lochet, E. Gilabert, Experimental determination of intragranular helium diffusion rates in boron carbide $\left(\mathrm{B}_{4} \mathrm{C}\right)$, J. Nucl. Mater. 527 (2019) 151834. doi: 10.1016/j.jnucmat.2019.151834

[16] M. Gérardin, E. Gilabert, D. Horlait, M-F. Barthe, G. Carlot, Experimental study of the diffusion of $\mathrm{Xe}$ and $\mathrm{Kr}$ implanted at low concentrations in $\mathrm{UO}_{2}$ and determination of their trapping mechanisms., J. Nucl. Mater. 556 (2021) 153174 doi: 10.1016/j.jnucmat.2021.153174

[17] C. Jiang, J. Nicolaï, A. Declémy, E. Gilabert, M.-F. Beaufort, J.-F. Barbot, The influence of the microstructure evolution on the surface morphology in the annealing process of helium-implanted spinel, Nucl. Instr. Meth. B374 (2016) 71-75. doi: 10.1016/j.nimb.2016.01.002

[18] C. Viaud, S. Maillard, G. Carlot, C. Valot, E. Gilabert, T. Sauvage, C. Peaucelle, N. Moncoffre, Behaviour of helium after implantation in molybdenum, J. Nucl. Mater. 385 (2009) 294-298. doi: 10.1016/j.jnucmat.2008.12.005

[19] Y. Yang, C. Zhang, L. Zhou, B. Li, The influence of the microstructure evolution on the surface morphology in the annealing process of helium-implanted spinel, Nucl. Instr. Meth. $\mathbf{B 2 6 6}$ (2008) 5132-5136. doi: 10.1016/j.nimb.2008.10.005

[20] A. van Veen, W.T.M. Buters, T.R. Armstrong, B. Nielsen, K.T. Westerduin, L.M. Caspers, J.T.M. de Hosson, Redistribution of implanted noble gas atoms by self-interstitials in molybdenum and nickel, Nucl. Instr. Meth. B209-210 (1983) 1055-1061. doi: 10.1016/0167-5087(83)90920-1

[21] G. Hultquist, M.J. Graham, J.L. Smialek, B. Jönsson, Hydrogen in metals studied by Thermal Desorption Spectroscopy (TDS), Corr. Sci. 93 (2015) 324-326. doi: 10.1016/j.corsci.2015.01.003

[22] D. Pérez Escobar, K. Verbeken, L. Duprez, M. Verhaege, Evaluation of hydrogen trapping in high strength steels by thermal desorption spectroscopy, Mater. Sci. Eng. A 551 (2012) 50-58. doi: 10.1016/j.msea.2012.04.078

[23] M. Tonks, D. Andersson. R. Devanathan, R. Dubourg, A. El-Azab, M. Freyss, F. Iglesias, K. Kulacsy, G. Pastore, S.R. Phillpot, M. Welland Unit mechanisms of fission gas release: Current understanding and future needs, J. Nucl. Mater. 504, (2018) 300-317. doi: 10.1016/j.jnucmat.2018.03.016

[24] W. Miekeley, F.W. Felix, Effect of stoichiometry on diffusion of xenon in $\mathrm{UO}_{2}$, J. Nucl. Mater. 42 (1972) 297-306. doi: 10.1016/0022-3115(72)90080-3

[25] K. Une, K. Nogita, S. Kashibe, M. Imamura, Microstructural change and its influence on fission gas release in high burnup $\mathrm{UO}_{2}$ fuel, J. Nucl. Mater. 188 (1992) 65-72. doi: 10.1016/00223115(92)90455-T

[26] D.A. Andersson, P. Garcia, X.-Y. Liu, G. Pastore, M. Tonks, P. Millett, B. Dorado, D.R. Gaston, D. Andrs, R.L. Williamson, R.C. Martineau, B.P. Uberuaga, C.R. Stanek, Atomistic modeling of intrinsic and radiation-enhanced fission gas (Xe) diffusion in $\mathrm{UO}_{2 \pm x}$ : Implications for nuclear fuel performance modeling, J. Nucl. Mater. 451 (2014) 225-242. doi: 10.1016/j.jnucmat.2014.03.041

[27] B. Lavielle, B. Thomas, E. Gilabert, G. Canchel, D. Horlait, S. Topin, F. Pointurier, C. Moulin, Development towards a double focusing isotopic separator for noble gas isotope enrichment, $J$. Mass Spectrom. 51 (2016) 718-23. doi: 10.1002/jms.3800

[28] E. Gilabert, B. Lavielle, B. Thomas, S. Topin, F. Pointurier, C. Moulin, Ultratrace analysis of krypton isotopes by resonant ionization spectroscopy-time of flight mass spectrometry (RIS-TOF), J. Anal. At. Spectrom. 31, (2016) 994-1001. doi: 10.1039/C5JA00423C

[29] https://www.lesker.com/newweb/flanges/flanges_technicalnotes_conflat_1.cfm 
[30] S. Katz, N. Kaplan, I. Grossinger, Using Diffractive Optical Elements, Laser Technik J. 15 (2018) 29-32. doi: 10.1002/latj.201800021

[31] J.R. Markham, P.R. Solomon, and P.E. Best, An FT-IR based instrument for measuring spectral emittance of material at high temperature, Rev. Sci. Instr. 61 (1990) 3700-3708. doi: $10.1063 / 1.1141538$

[32] O. Rozenbaum, D. De Sousa Meneses, Y. Auger, S. Chermanne, P. Echegut, A spectroscopic method to measure the spectral emissivity of semi-transparent materials up to high temperature, Rev. Sci. Instr. 70 (1999) 4020-4025. doi: 10.1063/1.1150028

[33] G.T. Lawrence, A review of the diffusion coefficient of fission-product rare gases in uranium dioxide, J. Nucl. Mater., 71 (1978), 195-218. doi: 10.1016/0022-3115(78)90418-X.

[34] H. Matzke, Gas release mechanisms in $\mathrm{UO}_{2}$ - a critical review, Radiat. Eff. 53 (1980) 219-242. doi: $10.1080 / 00337578008207118$

[35] P. Lösönen, On the behaviour of intragranular fission gas in $\mathrm{UO}_{2}$ fuel, J. Nucl. Mater., 280 (2000), 56-72. doi: 10.1016/S0022-3115(00)00028-3

[36] C. Ronchi, Thermophysical properties affecting safety and performance of nuclear fuel, High Temp., 45 (2007), 552-571. doi: 10.1134/S0018151X07040177

[37] J. Rest, M.W.D. Cooper, J. Spino, J.A. Turnbull, P. Van Uffelen, C.T. Walker, Fission gas release from $\mathrm{UO}_{2}$ nuclear fuel: A review, J. Nucl. Mater. 513 (2019) 310-345. doi: 10.1016/j.jnucmat.2018.08.019

[38] K. Une, K. Nogita, S. Kashibe, M. Imamura, Microstructural change and its influence on fission gas release in high burnup $\mathrm{UO}_{2}$ fuel, J. Nucl. Mater. 188 (1992) 65-72. doi: 10.1016/00223115(92)90455-T

[39] D.A. Andersson, P. Garcia, X.-Y. Liu, G. Pastore, M. Tonks, P. Millett, et al., Atomistic modeling of intrinsic and radiation-enhanced fission gas (Xe) diffusion in $\mathrm{UO}_{2 \pm x}$ : Implications for nuclear fuel performance modeling, J. Nucl. Mater. 451 (2014) 225-242. doi: 10.1016/j.jnucmat.2014.03.041

[40] W. Miekeley, F.W. Felix, Effect of stoichiometry on diffusion of xenon in $\mathrm{UO}_{2}$, J. Nucl. Mater. 42 (1972) 297-306. doi: 10.1016/0022-3115(72)90080-3

[41] A. Michel, Etude du comportement des gaz de fission dans le dioxyde d'uranium : mécanismes de diffusion, nucléation et grossissement de bulles, PhD thesis, University of Caen, 2011.

[42] J.F. Ziegler, J.P. Biersack, U. Littmark, The stopping power and range of ions in solids, Pergamon, New-York, 1985. doi: 10.1007/978-3-642-68779-2_5. www.srim.org.

[43] P.C. Held, D.R. Wilder, High-temperature hemispherical spectral emittance of uranium oxides at 0.65 and $0.70 \mu \mathrm{m}, \quad J$. Am. Ceram. Soc. 52 (1969) 182-185. doi: 10.1111/j.11512916.1969.tb13361.x

[44] J.K. Fink, Thermophysical properties of uranium dioxide, J. Nucl. Mater. 279 (2000) 1-18. doi: 10.1016/0022-3115(81)90541-9

[45] R. Lindner, Diffusion von Xe-133 in Uranoxyd verschiedenen Sauerstoffgehaltes, Zeitschrift Für Naturforschung A. 14 (1959) 582-584. doi: 10.1515/zna-1959-5-617 
[46] C. Onofri, C. Sabathier, C. Baumier, C. Bachelet, D. Drouan, M. Gérardin, M. Legros, Extended defect change in $\mathrm{UO}_{2}$ during in situ TEM annealing, Acta Mater. 196 (2020) 240-251. doi: 10.1016/j.actamat.2020.06.038

[47] C. Onofri, C. Sabathier, G. Carlot, D. Drouan, C. Bachelet, C. Baumier, M. Gérardin, M. Bricout, Changes in voids induced by ion irradiations in $\mathrm{UO}_{2}$ : In situ TEM studies, Nucl. Instrum. Meth. Phys. B 463 (2020) 76-85. doi: 10.1016/j.nimb.2019.11.031

[48] M. Bricout, G. Gutierrez, C. Baumier, C. Bachelet, D. Drouan, F. Garrido, C. Onofri, Synergy of electronic and nuclear energy depositions on the kinetics of extended defects formation in $\mathrm{UO}_{2}$, based on in situ TEM observations of ion-irradiation-induced microstructure evolution, J. Nucl. Mater. 554 (2021) 153088. doi: 10.1016/j.jnucmat.2021.153088

[49] G. Martin, C. Sabathier, J. Wiktor, S. Maillard, Molecular dynamics study of the bulk temperature effect on primary radiation damage in uranium dioxide, Nucl. Instrum. Meth. Phys. B 352 (2015) 135-139. doi: 10.1016/j.nimb.2014.12.008

[50] M.J. Rahman, M.W.D. Cooper, B. Szpunar, J.A. Szpunar, Primary radiation damage on displacement cascades in $\mathrm{UO}_{2}, \mathrm{ThO}_{2}$ and $\left(\mathrm{U}_{0.5} \mathrm{Th}_{0.5}\right) \mathrm{O}_{2}$, Comput. Mater. Sci. 154 (2018) 508-516. doi: 10.1016/j.commatsci.2018.08.024

[51] L. Van Brutzel, M. Rarivomanantsoa, Molecular dynamics simulation study of primary damage in UO2 produced by cascade overlaps, J. Nucl. Mater. 358 (2006) 209-216. doi: 10.1016/j.jnucmat.2006.07.009

[52] E. Gilabert, D. Horlait, M.-F. Barthe, P. Desgardin, M.-L. Amany, G. Carlot, M. Gérardin, S. Maillard, T. Wiss, Behavior of fission gases and $\mathrm{He}$ in $\mathrm{UO}_{2}$, INSPYRE D2.2 public deliverable, 2021, soon available at http://www.eerajpnm.eu/inspyre/filesharer/documents/Deliverables\%20\&\%20Milestones/Public\%20deliverables 


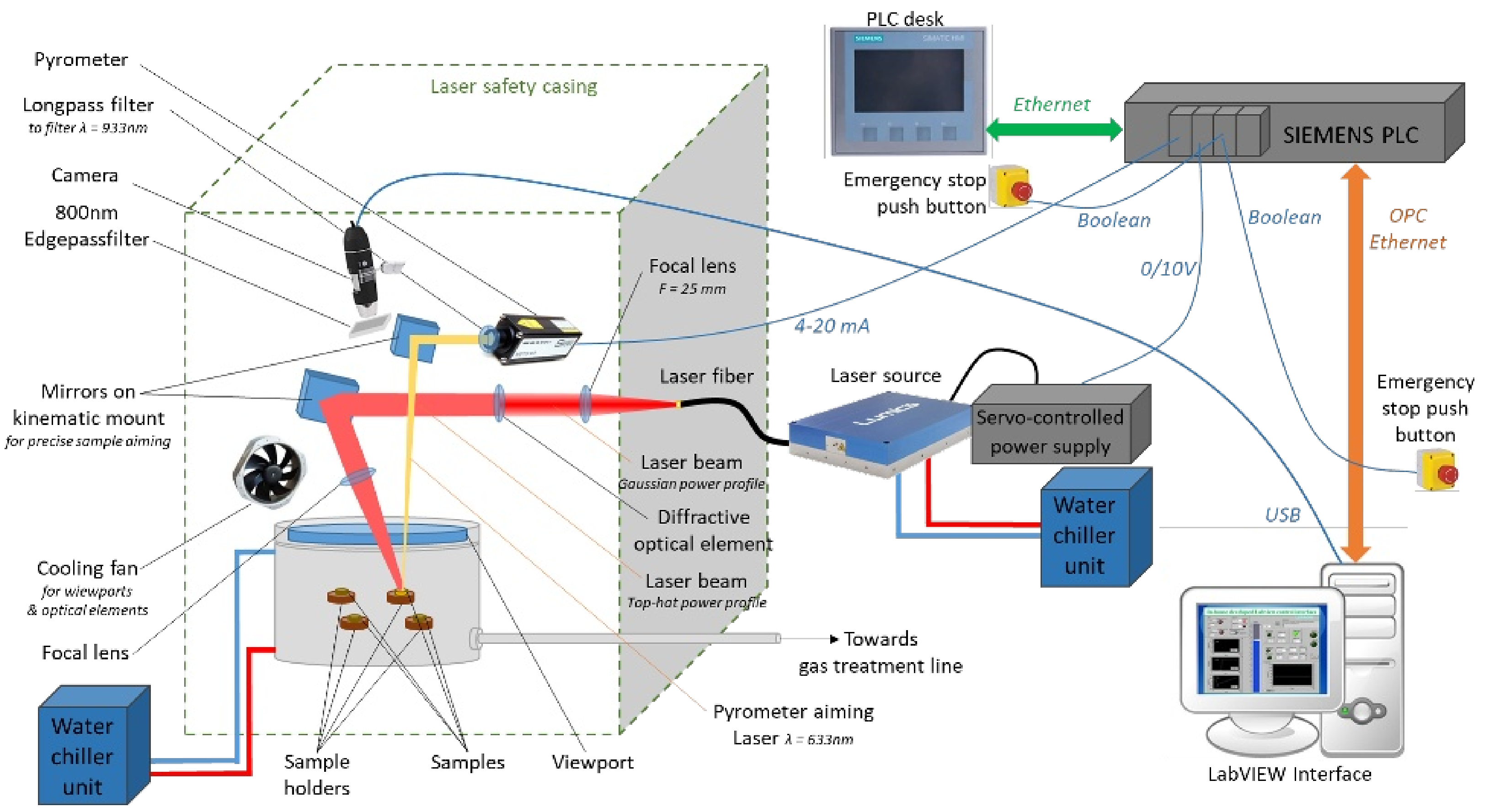




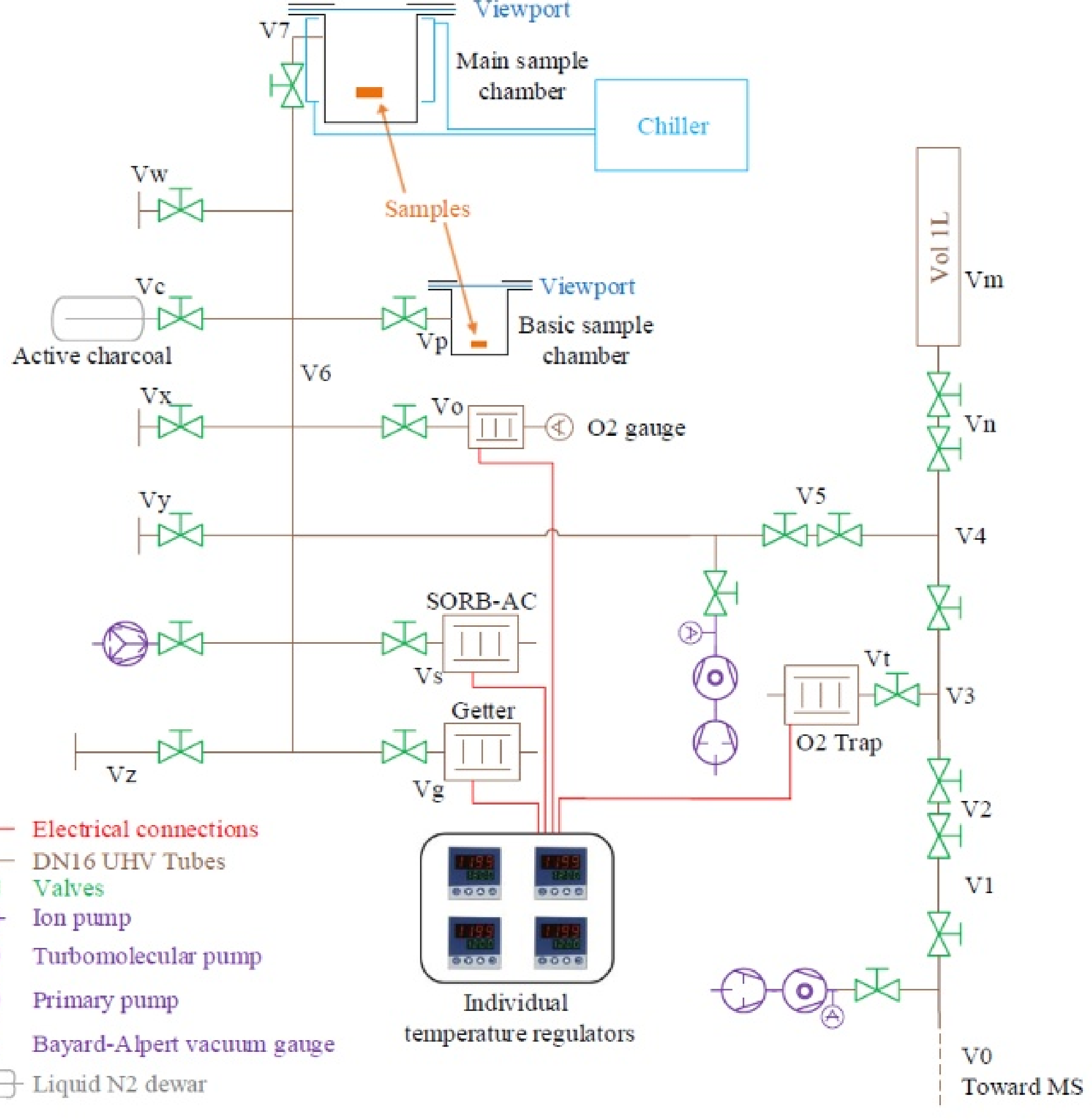




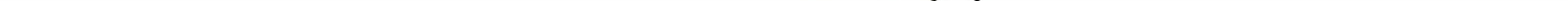



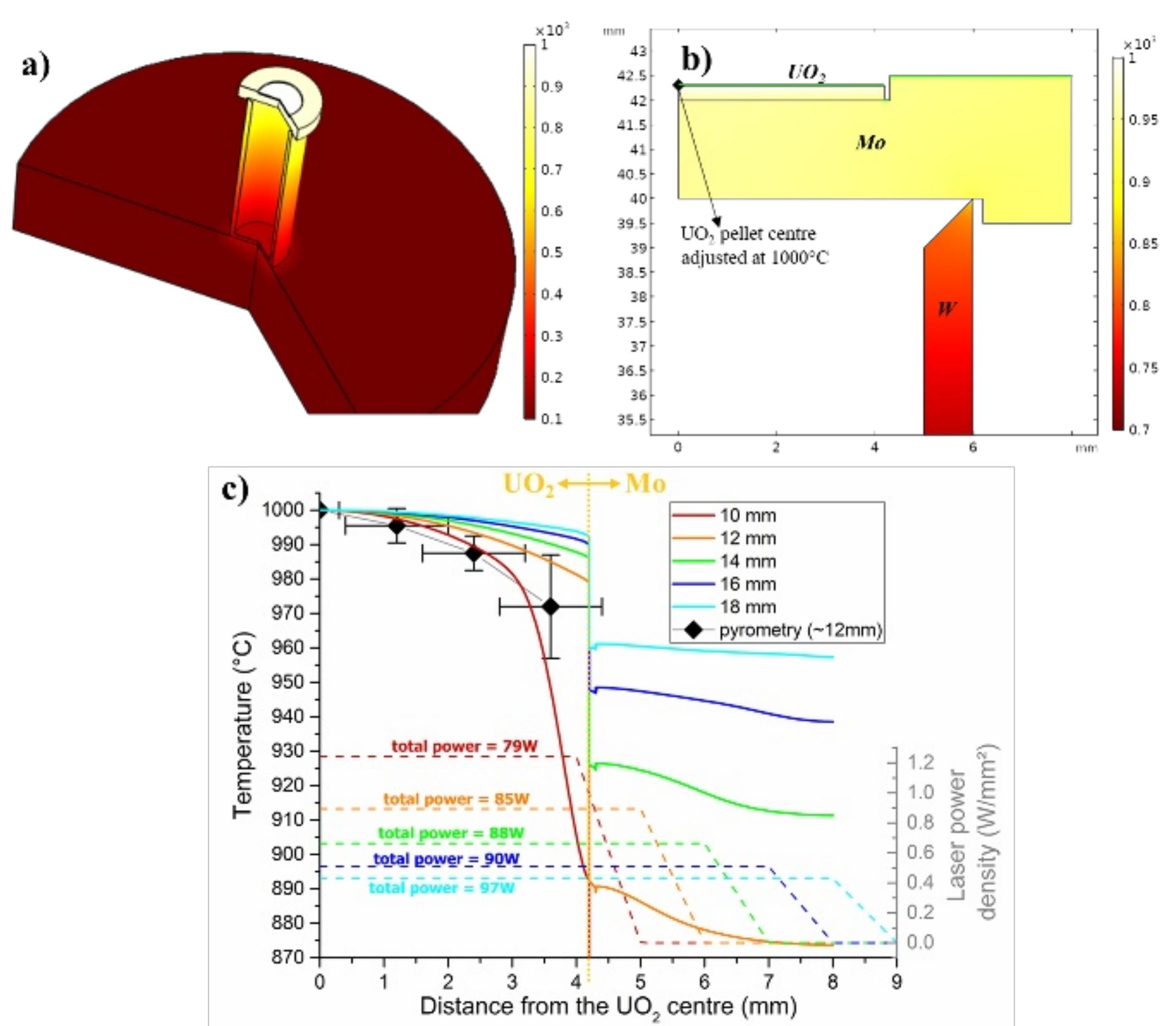


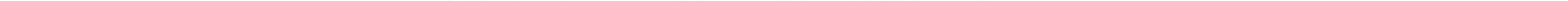

